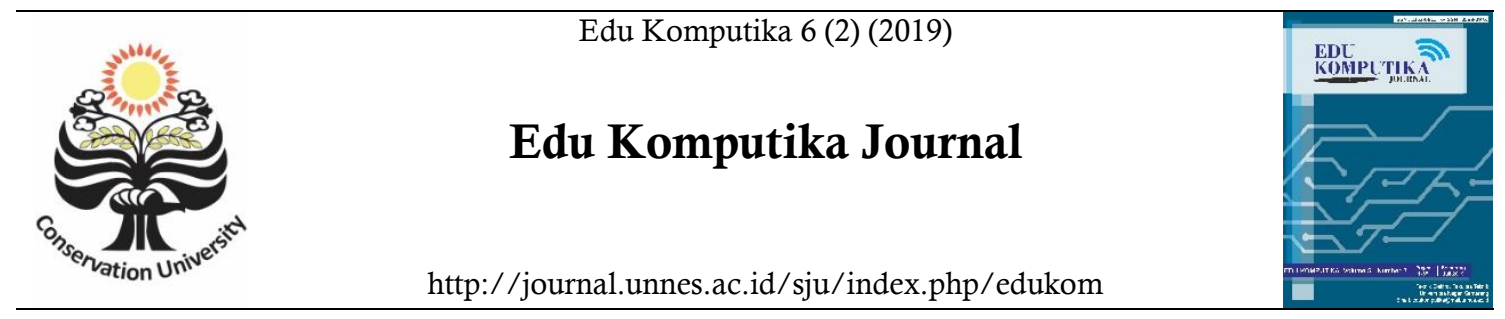

\title{
Analisis Usabilitas pada Sistem Monitoring Dan Otomasi Greenhouse untuk Budidaya Tanaman Cabai Berbasis Android
}

\section{Lian Cahyo Wijaya ${ }^{\bowtie}$}

Jurusan Teknik Komputer, Fakultas Teknik, Universitas Diponegoro, Indonesia

\section{Info Artikel}

Sejarah Artikel:

Diterima: September

2019

Direvisi: Desember 2019

Disetujui: Desember 2019

\section{Keywords:}

Antarmuka, Android,

Greenhouse, Usability,

SEQ, SUS

\begin{abstract}
Abstrak
Pemantauan dan kontrol greenhouse cabai menggunakan perangkat bergerak berbasis Android membutuhkan sebuah aplikasi dengan tampilan antarmuka pengguna yang benar agar mudah dimengerti dan digunakan oleh pengguna. Maka diperlukan sebuah rancangan antarmuka aplikasi greenhouse yang benar dan sudah teruji usabilitasnya untuk digunakan pengguna. Metode untuk pengujian antarmuka pengguna menggunakan pengujian SUS posttask dengan metode SUS dan poststudy dengan metode SEQ. Pengujian SEQ untuk mengukur tingkat kemudahan setiap fungsi desain aplikasi yang dikembangkan dan pengujian SUS untuk mengukur usability desain aplikasi. Hasil penelitian ini adalah sebuah antarmuka aplikasi pada sistem otomasi dan monitoring pada greenhouse dengan komunikasi nirkabel berbasis Android. Antarmuka ini berhasil diuji menggunakan pengujian usability post-task menggunakan metode SEQ dengan nilai median 7 dapat diartikan sangat mudah digunakan dan pengujian poststudy menggunakan metode SUS dengan nilai 75,13 dapat diartikan baik.
\end{abstract}

\begin{abstract}
Chili Greenhouse monitoring and control using mobile-based devices requires an application with the correct user interface to be easily understood and used by users. Then we need a greenhouse application interface design that is correct and has been tested for usability for user use. The method for testing user interface uses SUS post-task testing with SUS method and poststudy with SEQ method. SEQ testing to measure the ease of each application design function developed and SUS testing to measure application design usability. The results of this study are an Android-based user interface on an automation and monitoring system in a greenhouse with wireless communication This user interface was successfully tested using a post-task usability test using the SEQ method with a median value of 7 which means very easy to use and poststudy testing using the SUS method with a value of 75.13 which means good.
\end{abstract}




\section{PENDAHULUAN}

Seiring perkembangan zaman perangkat bergerak sangat berpengaruh besar terhadap kehidupan di negara ini. Banyak pekerjaan yang telah menggunakan teknologi perangkat bergerak khususnya pada sektor pertanian. Sektor pertanian sangat membantu dalam perekonomian dan kebutuhan pangan di Indonesia. Pada jangka tahun 2012-2016 luas lahan pertanian di Indonesia mengalami fluktuasi(Sekretariat, 2017:3).

Salah satu tanaman yang ditanam di Indonesia adalah cabai karena mayoritas masyarakat Indonesia mengonsumsi cabai. Pada umumnya, cabai merah ditanam di tempat terbuka pada akhir musim hujan atau menjelang musim kemarau, dengan tujuan untuk mengurangi atau menghindari kendala-kendala yang terjadi secara alamiah, yang biasa terjadi pada musim hujan. Tingginya kelembaban di sekitar tanaman karena curah hujan dapat menyebabkan pesatnya perkembangan penyakit. Selain itu, apabila hujan lebat, banyak bunga dan bakal buah yang gugur serta busuk. Sebaliknya masalah yang mungkin timbul di musim kemarau adalah terbatasnya ketersediaan sumber daya air, sehingga tidak selalu tersedia dalam kuantitas, kualitas dan pada lokasi serta waktu di mana dibutuhkan(Sumarna, 2012:15).

Untuk mengatasi pengaruh tempat dan cuaca maka diperlukan tempat tertutup untuk menanam cabai agar tanaman terlindungi dari pengaruh perubahan cuaca dapat menggunakan greenhouse. Greenhouse merupakan bangunan dengan dinding dan atap berbahan plastik atau kaca. Dimana greenhouse berfungsi untuk memanipulasi kondisi ruang menjadi sesuai dengan kebutuhan dari tanaman antara lain dapat mengatur suhu, kelembapan, intensitas cahaya, suplai air, pupuk, mencegah hama dan mencegah penyakit.

Pada greenhouse dibuat alat untuk memantau dan kontrol greenhouse berbasis Internet of Things (IoT). Untuk memantau dan kontrol dibutuhkan aplikasi pada perangkat bergerak. Oleh karena itu, dalam tugas akhir ini penulis bermaksud untuk membuat antarmuka yang terhubung dengan alat otomatisasi dan monitoring greenhouse agar petani dapat membantu petani dalam mengontrol dan mengolah data yang ada di dalam greenhouse secara real time. Desain antarmuka memiliki peran penting karena sebagai penghubung antara sistem dengan pengguna. Desain antarmuka harus dibuat dengan benar, karena akan membentuk persepsi para pengguna terhadap aplikasi yang digunakan dan juga harus memperhatikan kemudahan penggunaan agar dapat diterima oleh pengguna itu sendiri. Untuk menguji antarmuka pengguna dan pengalaman pengguna dibutuhkan pengujian usability. Pengujian post-task menggunakan metode Single Ease Question (SEQ) dan pengujian poststudy menggunakan metode System Usability Scale (SUS).

Rumusan masalah dalam penelitian ini adalah bagaimana merancang antarmuka pengguna pada sistem monitoring dan otomasi greenhouse. Bagaimana menguji antarmuka pengguna dan pengalaman pengguna pada antarmuka pengguna aplikasi greenhouse.

Tujuan dari penelitian ini adalah merancang sebuah antarmuka pengguna pada sistem otomasi dan monitoring pada greenhouse berbasis Android. Mengetahui tingkat usability antarmuka pengguna pada sistem otomasi dan monitoring pada greenhouse berbasis Android.

\section{METODE PENELITIAN}

Penelitian ini bertujuan untuk merancang antarmuka pengguna aplikasi monitoring dan kontrol greenhouse berbasis Android. Prosedur perancangan antarmuka pengguna mengacu pada prosedur perancangan desain antarmuka pengguna aplikasi perangkat Android. Terdapat beberapa tahapan dalam perancangan desain antarmuka pengguna aplikasi berbasis Android seperti pada Gambar 1 di bawah ini:
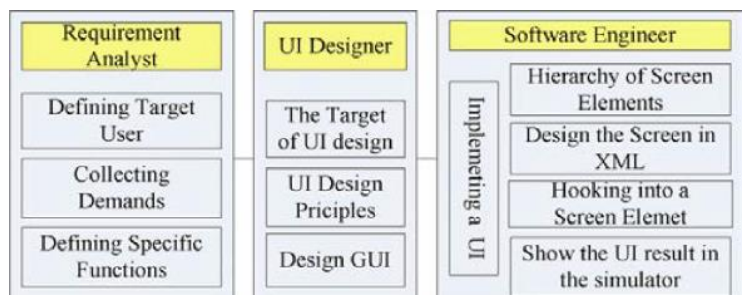

Gambar 1. Prosedur perancangan desain UI aplikasi mobile android

Prosedur pengembangan antarmuka pengguna memiliki tiga tahapan yaitu pada tahap analisis kebutuhan terbagi tiga, yaitu mendefinisikan target pengguna, mengumpulkan informasi tentang karakteristik target pengguna, dan mendefinisikan fungsi aplikasi secara spesifik. Pada tahap desain antarmuka juga dibagi menjadi tiga, yaitu target desain antarmuka, prinsip desain antarmuka, dan desain antarmuka. Lalu pada tahap implementasi antarmuka terbagi menjadi empat, yaitu hirarki elemen layar, merancang layar pada bahasa pemrograman XML, menghubungkan elemen layar, dan menampilkan hasil antarmuka pada simulator(Song, dkk, 2011:1). Mengacu 
dari prosedur pengembangan antarmuka pengguna aplikasi berbasis Android tahap-tahap penelitian dapat dilihat pada gambar 2 di bawah ini.

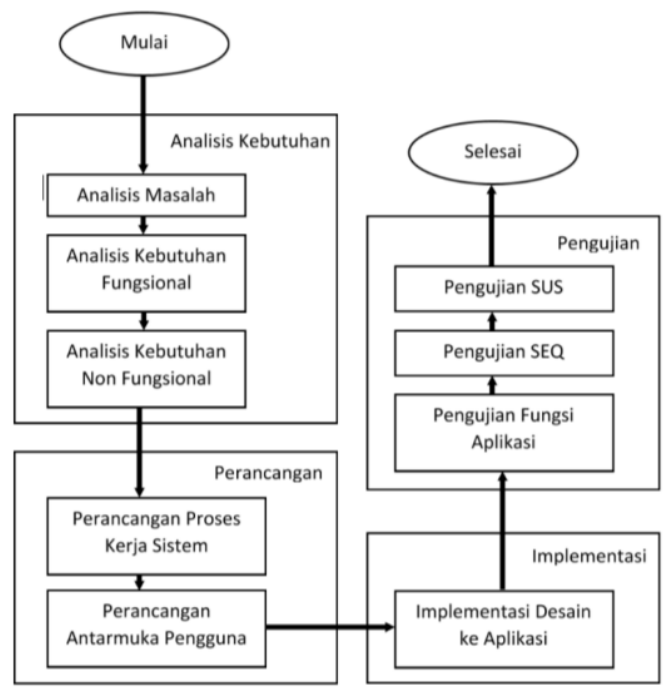

Gambar 2. Langkah-langkah penelitian

\section{Analisis dan Kebutuhan}

Pada tahap ini melakukan analisis terhadap masalah dan potensi pada penelitian ini. Pada penelitian ini dibutuhkan sebuah antarmuka pengguna untuk aplikasi greenhouse dengan tampilan yang sederhana dan mudah digunakan. Antarmuka harus dibuat sesuai prosedur agar aplikasi layak digunakan untuk pengguna. Dapat dianalisis kebutuhan desain dari kebutuhan fungsional dan non-fungsional yang diperlukan untuk membuat sistem. Pengguna ditargetkan untuk pengguna berumur di usia 18 tahun atau sudah dewasa(Undangundang, 2002:2), terbiasa menggunakan ponsel pintar, dan pengguna yang berada pada bidang pertanian, perkebunan, atau lingkungan. Sebelumnya dapat digambarkan menggunakan diagram use case dengan pengguna sebagai aktor dan beberapa komponen use case melihat suhu dan kelembaban tanah, mengatur kondisi lampu, kipas, dan pompa, melihat grafik suhu dan kelembaban tanah, mencadangkan basis data, memulihkan basis data, mengekspor data suhu dan kelembaban tanah ke Excel. Berikut diagram use case dapat dilihat pada Gambar 3.

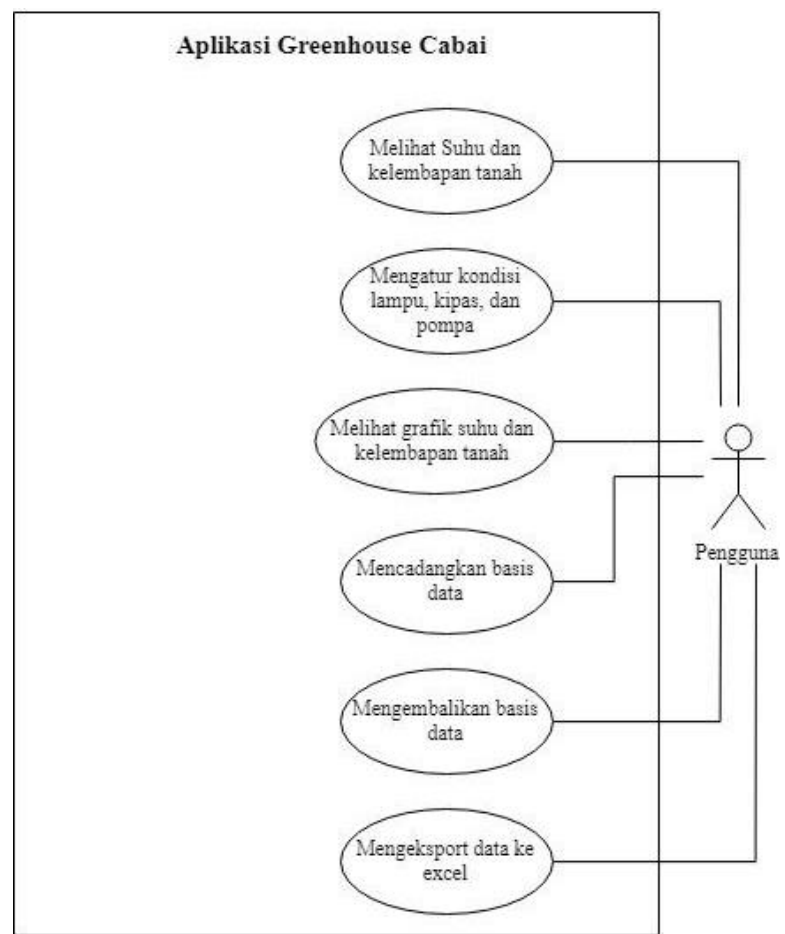

Gambar 3. Diagram use case

Deskripsi dari masing-masing komponen diagram use case pengguna dengan deskripsi Tabel 1 .

Tabel 1. Deskripsi Use Case Pengguna

\begin{tabular}{|c|c|c|}
\hline No & Use case & Deskripsi \\
\hline 1. & $\begin{array}{l}\text { Melihat suhu dan } \\
\text { kelembapan tanah }\end{array}$ & $\begin{array}{l}\text { Berisi data realtime } \\
\text { dari perangkat yang } \\
\text { dikirim-kan } \\
\text { smartphone }\end{array}$ \\
\hline 2. & $\begin{array}{l}\text { Mengatur kondisi } \\
\text { lampu, kipas, dan } \\
\text { pompa }\end{array}$ & $\begin{array}{l}\text { Proses pengaturan } \\
\text { kondisi menyalakan } \\
\text { dan mematikan } \\
\text { lampu, kipas, dan } \\
\text { pompa. }\end{array}$ \\
\hline 3. & $\begin{array}{l}\text { Melihat grafik } \\
\text { suhu dan } \\
\text { kelembapan tanah }\end{array}$ & $\begin{array}{l}\text { Berisi grafik dari } \\
\text { basis data suhu dan } \\
\text { kelembapan tanah }\end{array}$ \\
\hline 4. & $\begin{array}{l}\text { Mencadangkan } \\
\text { basis data }\end{array}$ & $\begin{array}{l}\text { Proses } \\
\text { mencadangkan basis } \\
\text { data sistem aplikasi } \\
\text { ke penyimpanan } \\
\text { smartphone }\end{array}$ \\
\hline 5. & $\begin{array}{l}\text { Mengembalikan } \\
\text { basis data }\end{array}$ & $\begin{array}{l}\text { Proses } \\
\text { mengembalikan } \\
\text { basis data dari } \\
\text { penyimpanan } \\
\text { smartphone ke sistem } \\
\text { aplikasi }\end{array}$ \\
\hline 6. & $\begin{array}{l}\text { Mengekspor data } \\
\text { ke Excel }\end{array}$ & $\begin{array}{l}\text { Proses ekspor basis } \\
\text { data aplikasi ke } \\
\text { bentuk Excel }\end{array}$ \\
\hline
\end{tabular}

Sumber: Hasil Olahan Penulis 2019 
Berdasarkan analisis use case terdapat aktor pengguna yang memiliki beberapa kebutuhan fungsional yaitu aplikasi dapat menampilkan data secara realtime suhu dan kelembaban tanah, aplikasi dapat menampilkan grafik dari basis data yang tersimpan, aplikasi dapat mencadangkan basis data ke penyimpanan smartphone, aplikasi dapat memulihkan basis data dari penyimpanan smartphone, aplikasi dapat mengekspor basis data ke dalam bentuk Excel.

Kebutuhan non fungsional adalah kebutuhan yang tidak terdapat pada sistem aplikasi Greenhouse Cabai yaitu antarmuka digunakan untuk aplikasi perangkat bergerak berbasis Android, aplikasi dapat digunakan pada Android 5.0 Lollipop ke atas.

\section{Perancangan}

Pada tahap perancangan terdapat tahap perancangan proses kerja sistem untuk mengetahui perilaku aktivitas sistem aplikasi ketika aplikasi dijalankan. Dapat digambarkan melalui diagram aktivitas. Pada sistem ini terdapat diagram aktivitas pengguna yang dapat melihat kondisi suhu dan kelembaban tanah, mengatur lampu, kipas, dan pompa, kemudian melihat grafik, mencadangkan, mengembalikan, dan mengekspor basis data. Berikut gambar diagram aktivitas pengguna pada Gambar 4 .

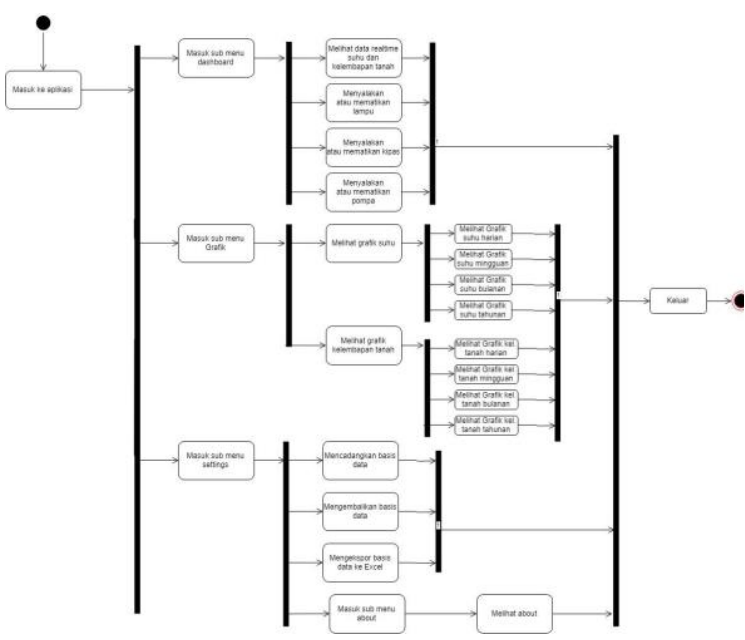

Gambar 4. Diagram aktivitas pengguna

Setelah itu dibuat perancangan desain mockup antarmuka pengguna menggunakan aplikasi Adobe XD dengan hasil sebagai berikut.

Pada Gambar 5(a) layout splash screen ini berisi tampilan awal aplikasi menampilkan logo dan nama aplikasi. Pada Gambar 5(b) layout halaman utama berisi tampilan data realtime suhu dan kelembapan. Kemudian tampilan dan tombol kontrol lampu, kipas, dan pompa.

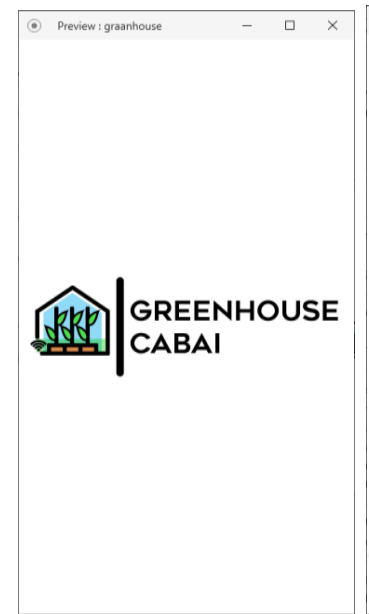

(a)

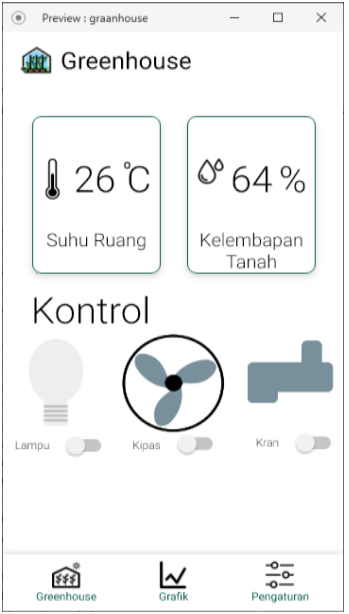

(b)
Gambar 5. (a) Splashscreen, (b) Halaman utama

Pada Gambar 6(a) layout grafik menampilkan grafik suhu dan kelembapan tanah dengan data yang diambil dari basis data aplikasi. Pada Gambar 6(b) layout pengaturan berisi pilihan untuk mencadangkan, memulihkan, dan mengekspor ke bentuk Excel dari basis data aplikasi.

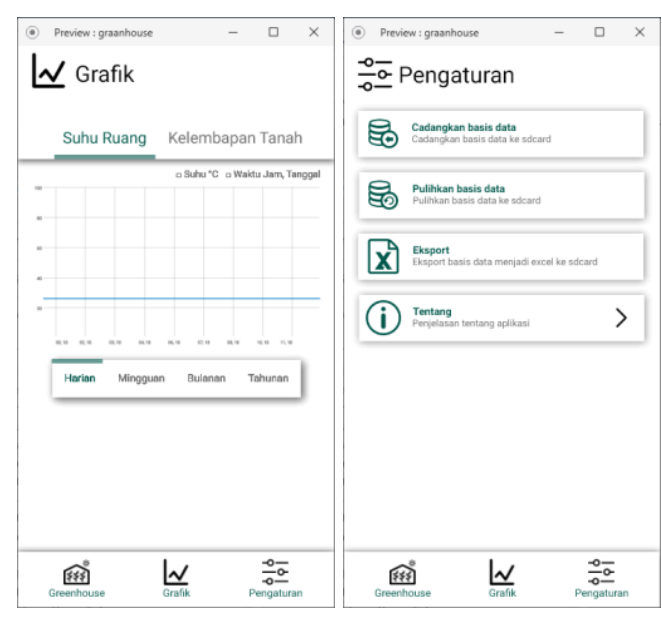

(a)

(b)

\section{Gambar 6. (a) Halaman grafik, (b) Halaman pengaturan}

Pada Gambar 7 layout tentang berisi penjelasan pembuat aplikasi dan tujuan pembuatan aplikasi dengan terdapat logo aplikasi dan footer. 


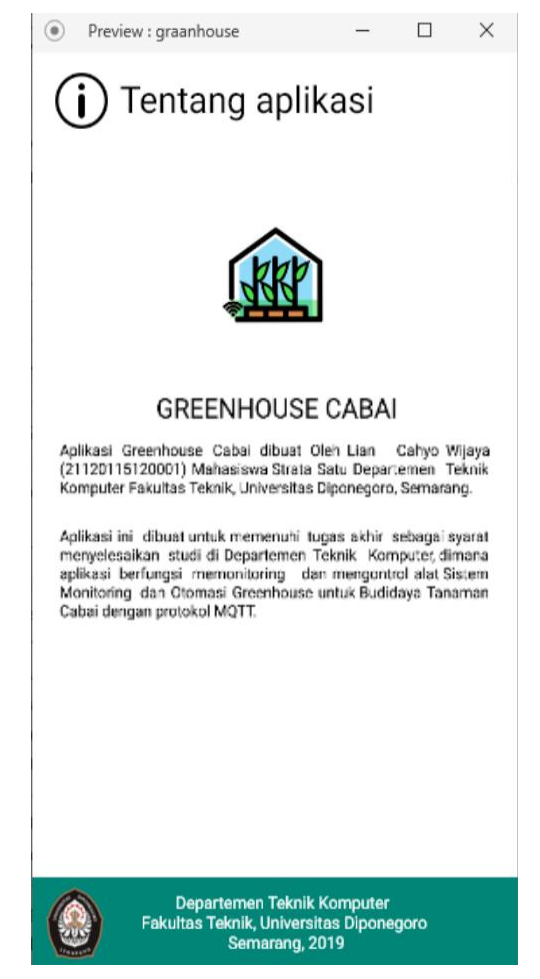

Gambar 7. Halaman tentang aplikasi

3. Implementasi

Selanjutnya pada tahap implementasi dilakukan pengubahan dari bentuk desain antarmuka pengguna dari Adobe XD menjadi tulisan dengan bahasa layout XML pada Android Studio agar dapat dimengerti oleh komputer.

\section{Pengujian}

Setelah tahap implementasi adalah tahap pengujian. Untuk menguji antarmuka pengguna aplikasi menggunakan pengujian usability untuk mengetahui sejauh mana pengguna dapat belajar dan menggunakan aplikasi Greenhouse Cabai untuk mencapai tujuannya dan sejauh mana kepuasan pengguna dalam menggunakan aplikasi ditentukan dengan efektivitas, efisiensi, dan kepuasan dalam konteks penggunaan tertentu (Sauro \& Lewis, 2012:9).

Kuesioner yang direkomendasikan pengujian untuk Poststudy yaitu System Usability Scale (SUS) dan untuk Post-task yaitu Single Ease Question (SEQ) atau Subjective Mental Effort Question (SMEQ). SUS awalnya dikembangkan untuk menguji kepuasan pengguna dengan "quick and dirty". Kuesioner SUS menjadi salah satu kuesioner yang telah standar poststudy yang paling populer dengan praktis, dan penelitian baru-baru ini menunjukkan meskipun cepat namun jauh dari kata "dirty" (Sauro \& Lewis, 2012:186).

Pada penelitian ini akan digunakan pengujian post-task menggunakan metode Single Ease Question (SEQ) dan pengujian poststudy menggunakan metode System Usability Scale (SUS). Pengujian metode SUS menggunakan kuesioner yang telah disediakan dengan 10 pertanyaan dengan jawaban mulai dari sangat tidak setuju sampai sangat setuju dengan skala likert 1-5(Sharfina \& Santoso, 2016:146).

Pengujian SUS terdiri dari 10 pertanyaan dengan jawaban menggunakan skala likert 1 sampai 5. Pertanyaan nomor (1, 2, 3, 5, 6, 7, 8, dan 9) digunakan untuk menguji usable dan pertanyaan nomor (4 dan 10) digunakan untuk menguji learnable(Sharfina \& Santoso, 2016:146). Pertanyaan nomor ganjil merupakan pertanyaan positif dan pada nomor genap merupakan pertanyaan negatif (Sharfina \& Santoso, 2016:146). Untuk daftar pertanyaan pengujian SUS terdapat pada Tabel 2.

Tabel 2. Daftar Pertanyaan SUS

\begin{tabular}{cl}
\hline No & Pertanyaan \\
\hline 1. & Saya berpikir akan menggunakan sistem ini \\
lagi. \\
2.
\end{tabular}

Selanjutnya pada pengujian SEQ terdapat 6 tugas dari F1 hingga F6, di setiap tugas terdapat satu pertanyaan dengan jawaban skala likert 1 sampai 7 dari sangat sulit hingga sangat mudah. Untuk daftar tugas dan pertanyaan SEQ pada Tabel 3. 
Tabel 3. Daftar tugas SEQ

\begin{tabular}{|c|c|c|}
\hline No & Fungsi & Tugas \\
\hline F1 & $\begin{array}{l}\text { Melihat kondisi } \\
\text { suhu ruang dan } \\
\text { kelembapan tanah }\end{array}$ & $\begin{array}{l}\text { Pengguna masuk di } \\
\text { menu utama aplikasi } \\
\text { dan dapat memantau } \\
\text { kondisi suhu ruang dan } \\
\text { kelembapan tanah }\end{array}$ \\
\hline $\mathrm{F} 2$ & Mengontrol & $\begin{array}{l}\text { Pengguna masuk di } \\
\text { menu utama dan dapat } \\
\text { mengontrol lampu, } \\
\text { kipas, dan pompa. }\end{array}$ \\
\hline F3 & Melihat grafik & $\begin{array}{l}\text { Pengguna masuk ke } \\
\text { menu grafik, lalu } \\
\text { menampilkan grafik } \\
\text { suhu dan kelembapan } \\
\text { tanah, serta mengatur } \\
\text { kategori waktu harian, } \\
\text { mingguan, bulanan, dan } \\
\text { tahunan pada grafik }\end{array}$ \\
\hline $\mathrm{F} 4$ & $\begin{array}{l}\text { Cadangkan dan } \\
\text { pulihkan basis } \\
\text { data }\end{array}$ & $\begin{array}{l}\text { Pengguna masuk ke } \\
\text { menu pengaturan, lalu } \\
\text { mencadangkan data, } \\
\text { dan memulihkan data }\end{array}$ \\
\hline F5 & $\begin{array}{l}\text { Mengekspor data } \\
\text { ke Excel }\end{array}$ & $\begin{array}{l}\text { Pengguna mengekspor } \\
\text { data ke bentuk Excel } \\
\text { dan membuka file Excel }\end{array}$ \\
\hline F6 & $\begin{array}{l}\text { Melihat tentang } \\
\text { aplikasi }\end{array}$ & $\begin{array}{l}\text { Pengguna menekan } \\
\text { tombol tentang aplikasi } \\
\text { pada menu pengaturan } \\
\text { untuk menampilkan } \\
\text { penjelasan aplikasi }\end{array}$ \\
\hline
\end{tabular}

Sumber: Hasil Olahan Penulis 2019

\section{HASIL DAN PEMBAHASAN}

\section{Implementasi}

Hasil dari implementasi dari antarmuka pengguna diubah menjadi tampilan pada aplikasi Android yang telah berjalan pada perangkat Android dengan hasil sebagai berikut.

Pada Gambar 8 (a) layout splash screen ini berisi tampilan awal aplikasi menampilkan logo dan nama aplikasi. Pada Gambar 8(b) layout halaman utama berisi tampilan data realtime suhu dan kelembapan dengan hasil implementasi pada pengujian menunjukan temperatur $26^{\circ} \mathrm{C}$ dan kelembapan tanah bernilai $68 \%$. Kemudian tampilan dan tombol kontrol lampu, kipas, dan pompa pada pengujian lampu menyala lalu kipas dan pompa mati.

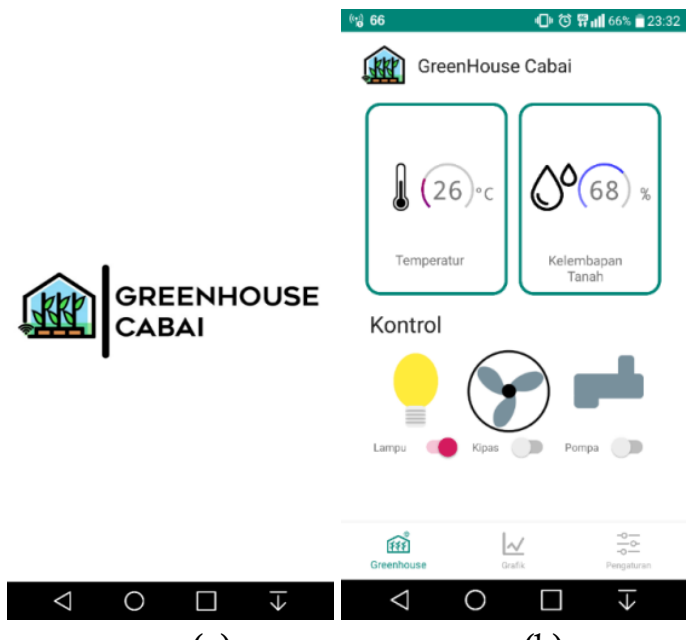

(a)

(b)

Pada Gambar 9 (a) adalah tampilan grafik suhu ruang dengan pada samping kiri grafik terdapat keterangan suhu dengan satuan ${ }^{\circ} \mathrm{C}$. Lalu di bawah grafik terdapat keterangan waktu. Dan di bawah keterangan waktu terdapat tombol untuk mengubah kategori waktu harian, mingguan, bulanan, dan tahunan. Pada gambar 9(b) halaman pengaturan terdapat empat menu yaitu cadangkan basis data, pulihkan basis data, ekspor, dan tentang aplikasi. Menu cadangkan basis data digunakan untuk mencadangkan data yang telah masuk setiap jamnya secara offline ke penyimpanan perangkat. Lalu menu pulihkan basis data untuk memulihkan data yang telah dicadangkan offline di penyimpanan perangkat ke aplikasi Greenhouse Cabai. Lalu pada menu ekspor untuk mengekspor data ke bentuk Excel agar dapat dilihat keseluruhan data suhu ruang dan kelembapan tanah pada tabel.

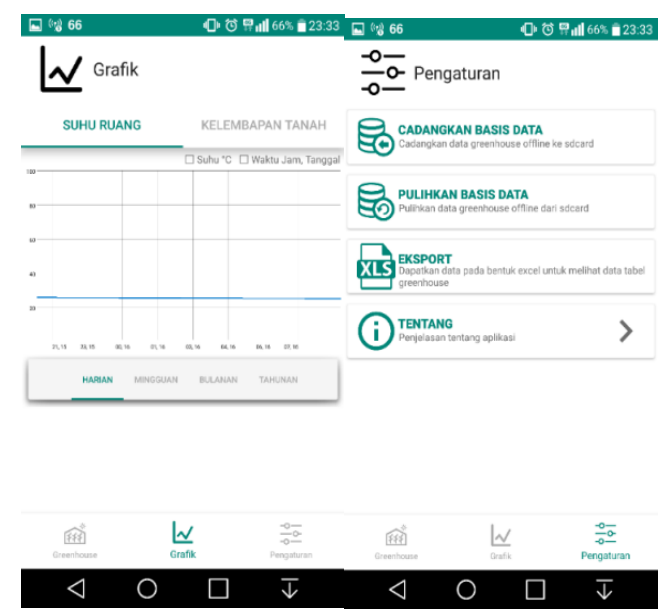

(a)

(b)

Gambar 9. (a) Halaman grafik, (b) Halaman pengaturan 
Pada gambar 10 tampilan halaman tentang aplikasi berisi penjelasan singkat tentang aplikasi yang dibuat.

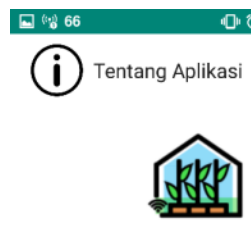

GREENHOUSE CABAI
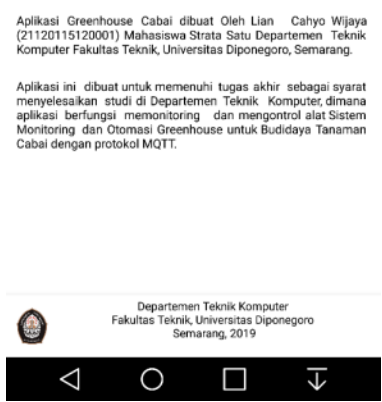

Gambar 10. Halaman tentang aplikasi

\section{Pengujian}

Dari pengujian yang dilakukan didapatkan hasil dari pengujian post-task dengan metode SEQ dengan tugas F1 sampa F6 didapatkan data dengan hasil pada tabel 4 .

Tabel 4. Hasil Pengujian SEQ

\begin{tabular}{ccccccc}
\hline \multirow{2}{*}{$\begin{array}{c}\text { Responden } \\
\text { No. }\end{array}$} & \multicolumn{6}{c}{ Nilai } \\
\cline { 2 - 6 } & F1 & F2 & F3 & F4 & F5 & F6 \\
\hline 1. & 7 & 7 & 6 & 7 & 7 & 7 \\
2. & 6 & 6 & 6 & 7 & 7 & 7 \\
3. & 6 & 6 & 5 & 6 & 6 & 7 \\
4. & 7 & 7 & 7 & 7 & 7 & 7 \\
5. & 7 & 7 & 7 & 7 & 7 & 7 \\
6. & 7 & 7 & 7 & 7 & 6 & 7 \\
7. & 7 & 7 & 6 & 6 & 7 & 7 \\
8. & 7 & 7 & 6 & 7 & 7 & 7 \\
9. & 6 & 6 & 6 & 6 & 5 & 6 \\
10. & 7 & 7 & 7 & 7 & 7 & 7 \\
11. & 7 & 7 & 7 & 7 & 7 & 7 \\
12. & 7 & 7 & 7 & 7 & 7 & 7 \\
13. & 6 & 6 & 6 & 6 & 6 & 6 \\
14. & 7 & 6 & 7 & 7 & 6 & 7 \\
15. & 6 & 6 & 6 & 6 & 6 & 6 \\
16. & 7 & 7 & 6 & 5 & 5 & 5 \\
17. & 6 & 7 & 5 & 7 & 7 & 6 \\
18. & 7 & 7 & 7 & 7 & 7 & 7 \\
19. & 7 & 7 & 6 & 7 & 7 & 7 \\
20. & 7 & 7 & 6 & 6 & 7 & 7 \\
\hline Sumber: Hasil Olahan Penulis 2019 & &
\end{tabular}

Lalu untuk mendapatkan nilai setiap tugasnya dari data tabel 4 diambil rata-ratanya didapatkan hasil sebagai berikut pada Tabel 5 .
Tabel 5. Hasil Pengujian SEQ

\begin{tabular}{ccccccc}
\hline $\begin{array}{c}\text { Pertan } \\
\text { yaan }\end{array}$ & F1 & F2 & F3 & F4 & F5 & F6 \\
\hline $\begin{array}{c}\text { Rata }- \\
\text { rata }\end{array}$ & 6,7 & 6,7 & 6,3 & 6,6 & $\begin{array}{c}6,5 \\
5\end{array}$ & 6,7 \\
$\begin{array}{c}\text { Nilai } \\
\text { Sumber: Hasil Olahan Penulis 2019 }\end{array}$ & & & \\
\hline
\end{tabular}

Sumber: Hasil Olahan Penulis 2019

Sehingga dapat ditampilkan grafik hasil pengujian post-task menggunakan metode SEQ pada Gambar 11.

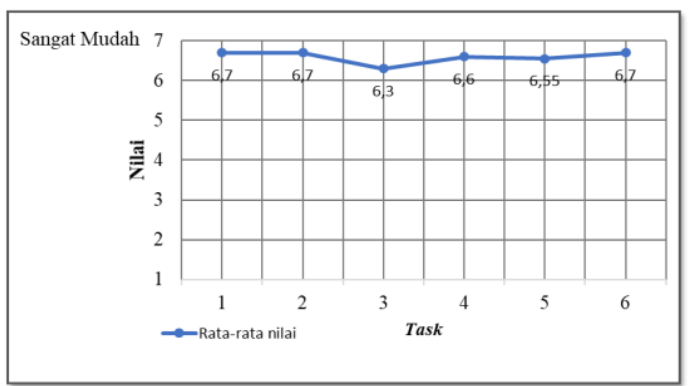

Gambar 11. Grafik hasil pengujian SEQ

Skala nilai untuk mendapatkan hasil akhir dari SEQ diambil dengan median. Maka hasil dari median seluruh tugas F1 sampai F6 adalah 7.

Selanjutnya pada pengujian poststudy menggunakan metode SUS diperoleh hasil dari kuesioner seperti pada Tabel 6 di bawah ini.

Tabel 6. Hasil Perhitungan Skor Pengujian SUS

\begin{tabular}{cccc}
\hline $\begin{array}{c}\text { Respon } \\
\text { den } \\
\text { No. }\end{array}$ & $\begin{array}{c}\text { Bobot Soal } \\
\text { Negatif }\end{array}$ & $\begin{array}{c}\text { Bobot Soal } \\
\text { Positif }\end{array}$ & $\begin{array}{c}\text { SUS Skor } \\
(\%)\end{array}$ \\
\hline 1. & 15 & 14 & 72,5 \\
2. & 15 & 15 & 75 \\
3. & 15 & 14 & 72,5 \\
4. & 14 & 15 & 72,5 \\
5. & 17 & 14 & 77,5 \\
6. & 16 & 14 & 75 \\
7. & 17 & 13 & 75 \\
8. & 20 & 16 & 90 \\
9. & 10 & 14 & 60 \\
10. & 20 & 17 & 92,5 \\
11. & 18 & 14 & 80 \\
12. & 17 & 14 & 77,5 \\
13. & 12 & 13 & 62,5 \\
14. & 14 & 19 & 82,5 \\
15. & 12 & 11 & 57,5 \\
16. & 13 & 13 & 65 \\
17. & 16 & 16 & 80 \\
18. & 19 & 10 & 72,5 \\
19. & 16 & 18 & 85 \\
20. & 16 & 15 & 77,5 \\
& Rata-rata Skor SUS & & 75,13 \\
\hline
\end{tabular}

Sumber: Hasil Olahan Penulis 2019 
Pada pengujian post-task menggunakan metode SEQ nilai median 7 dimana dilihat pada Tabel 7. skala SEQ mendapatkan hasil sangat baik menurut para responden.

Tabel 7. Skala Nilai SEQ

\begin{tabular}{cl}
\hline Skor & Hasil \\
\hline 1 & Sangat sulit \\
2 & Sulit \\
3 & Tidak mudah \\
4 & Cukup \\
5 & Tidak sulit \\
6 & Mudah \\
7 & Sangat mudah \\
\hline Sumber: (Santoso, 2018:178)
\end{tabular}

Selanjutnya pada pengolahan data dari pengujian poststudy dengan metode SUS pada Tabel 6 diperoleh rata-rata skor SUS sebesar 75,13 . Untuk skala penilaian metode SUS dapat dilihat pada Gambar 12(Bangor, dkk, 2009:121) yang berarti skor SUS sebesar 75,13 mendapatkan nilai $\mathrm{C}$ dan masuk kategori baik jika dikonversikan menurut kisaran rating penerimaan. Dengan demikian aplikasi Greenhouse Cabai berbasis Android memiliki usability yang baik menurut pada responden.

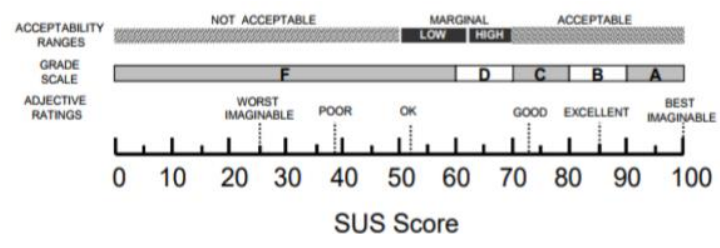

Gambar 12. Dasar Penilaian Skor SUS

\section{SIMPULAN}

Perancangan antarmuka aplikasi Greenhouse Cabai berbasis Android pada penelitian ini menggunakan Material Design untuk Android dengan antarmuka yang umum digunakan pada aplikasi perangkat bergerak. Aplikasi yang sudah dibuat dapat digunakan untuk monitoring dan kontrol alat pada greenhouse. Dari hasil penelitian menggunakan pengujian usability poststudy dengan metode SUS dengan skor rata-rata 75,13 dapat diartikan bernilai $C$ atau dikategorikan baik dan post-task dengan metode SEQ dengan median 7 yang dapat diartikan sangat mudah.

\section{SARAN}

Adapun saran untuk penelitian selanjutnya adalah melakukan pengujian task completion rate dan task time.

\section{UCAPAN TERIMA KASIH}

Ucapan terima kasih ditujukan kepada Dr. R. Rizal Isnanto, S.T., M.M., M.T., Teguh Martono, S.T., M.T., S.T., M.T., Dania Eridani, S.T., M.Eng., Ike Pertiwi Windasari, S.T., M.T. Seluruh dosen Departemen Teknik Komputer Fakultas Teknik Universitas Diponegoro. Serta teman-teman Teknik Komputer khususnya angkatan 2015.

\section{DAFTAR PUSTAKA}

Bangor, A., Kortum, P., \& Miller, J. 2009. Determining What Individual SUS Scores Mean: Adding an Adjective Rating Scale. J. Usability Stud.

Santoso, J. 2018. Usability User Interface dan User Experience Media Pembelajaran Kamus Kolok Bengkala Berbasis Android. JURNAL SISTEM DAN INFORMATIKA.

Sauro, J., \& Lewis, J. R. 2012. Quantifying The User Experience: Practical Statistics for User Research. Elsevier.

Sekretariat Jenderal - Kementerian Pertanian. 2017. Statistik Lahan Pertanian Tahun 2012-2016. Jakarta: Pusat Data dan Sistem Informasi Pertanian Sekretariat Jenderal - Kementerian Pertanian.

Sharfina, Z., \& Santoso, H. B. 2016. An Indonesian Adaptation of the System Usability Scale (SUS). 2016 International Conference on Advanced Computer Science and Information Systems.

Song, M., Song, H., \& Xiangling, F. 2011. Methodology of User Interfaces Design Based on Android. 2011 International Conference on Multimedia Technology (ICMT).

Sumarna, A. 2012. Irigasi Tetes pada Budidaya Cabai. Jurnal Agronomi Indonesia.

UNDANG-UNDANG REPUBLIK INDONESIA. 2002. UU No. 23 Tahun 2002 tentang Perlindungan Anak. http://pih.kemlu.go.id/files/UUNo23t ahun2003PERLINDUNGANANAK.p df. diakses 5 Mei 2016. 